\title{
Liberalismo y derecho \\ de petición durante la \\ república central en \\ México, 1835-1846
}

\section{Mariana Terán Fuentes ${ }^{1}$}

marianateranuaz@gmail.com

ORCID DOI: http://orcid.org/0000-0003-3602-9115

Mónica Pérez Navarro²

monicaprz@gmail.com

ORCID DOI: https://orcid.org/0000-0002-5631-

Liberalism and right of petition during

the central republic in Mexico, 1835-1846

\section{Resumen}

Este trabajo explica las maneras en que condición de individuos y no como parte el liberalismo asociado a las formas de gobierno federalistas, tuvo continuidad durante la república central en México (1836-1846) empleando el viejo derecho de petición por los ciudadanos en su de corporaciones. Ejercer el derecho de petición en este periodo de la historia de las formas de gobierno en la república, permitió abrir una nueva etapa en la cultura política mexicana.

Palabras clave: Derecho de petición, centralismo, federalismo, Zacatecas, siglo XIX.

\section{Abstract}

This paper explains the different forms citizens, as individuals, and not as part in which liberalism associated with federalist governments, manage to achieve continuity during the central republic in Mexico (1836-1846) putting into effect the old right of petition used by the of corporations. To exercise the right of petition in this period of the history of the forms of government in the republic, to open a new stage in Mexican political culture.

Keywords: Right of petition, centralism, federalism, Zacatecas, XIX century.

1 Campus Universitario II $2^{\circ}$ piso, Edificio "A" de Posgrados en Ciencias Sociales y Humanidades Av. Preparatoria s/n, C. P. 98068, Col. Hidráulica, Zacatecas, Zacatecas, México.

2 Instituto de Investigaciones Históricas, Universidad Autónoma de Baja California, Campus Tijuana, México.

Calzada Universidad 14418, C.P. 22427, Indeco Universidad, Tijuana, Baja California, México. 


\section{Introducción ${ }^{3}$}

En la República Mexicana, el estado de Zacatecas es un ejemplo de cómo el liberalismo se entendió en clave federal. Dios y libertad federal fue la rúbrica con la que se firmaron los documentos oficiales durante los primeros años de vida republicana. Entre 1824 y 1835 los esfuerzos de los políticos de aquella entidad se dirigieron a fortalecer el ejercicio de la libertad: de imprenta, de elección de autoridades, de proponer proyectos, representaciones o reformas por distintos actores políticos a las legislaturas. En la exposición de motivos de su primera carta constitucional del estado de Zacatecas (1825), se asociaba al pasado monárquico español con oscurantismo, esclavitud, absolutismo, despotismo; en contraparte, la república federal era sinónimo de libertad, independencia, división de poderes, derechos del hombre: "grabad en vuestros corazones la sabia e importante máxima del gran político Montesquieu: las naciones una vez se constituyen" (Galván, 1828, vol. II, p. 413).

En este sentido, el liberalismo zacatecano en clave federal significó un código o lectura específica de los principios liberales y particularmente, una apropiación del sistema federal referido a las condiciones peculiares de su entorno sociopolítico y económico. Implicó una férrea defensa de las prácticas que se consideraban necesarias para consolidar las libertades ciudadanas como garantías solo posibles en un entorno de pacto federal.

Las cartas constitucionales de las entidades federativas de la nueva nación republicana se preocuparon por establecer esas formas variadas de ejercer la libertad de los ciudadanos y de las corporaciones como lo fueron los ayuntamientos. A partir de 1825, los primeros artículos de las constituciones particulares de cada entidad la declararon libre, independiente y soberana.

Siguiendo con la tradición regionalista y municipalista enraizada desde las reformas borbónicas, el federalismo mexicano cobró vida por la fortaleza de su estructura provincial, caracterizado por una doble soberanía o soberanía compartida (Carmagnani, 1993). Mientras que en el Acta Constitutiva y en la Constitución Federal de 1824 los derechos de los ciudadanos estaban diluidos, en las constituciones estatales se formularon, en general, cuatro: libertad, seguridad, propiedad e igualdad. En algunas de estas constituciones el derecho de petición se prescribió de inicio; por

3 Una versión inicial se presentó en el marco de la Red temática de Cuerpos Académicos
(Promep) "Historia social y política de México". Agradecemos los comentarios de Brian
Connaughton, Norma Angélica Castillo y las recomendaciones que los dictaminadores
sugeridos por Letras Históricas hicieron al texto. 
ejemplo, la Constitución de San Luis Potosí de 1826, lo concibió como garante de los ciudadanos potosinos, aunque en su especificidad se reducía al derecho de representar ante el Congreso para reclamar la observancia de la Constitución (Galván, 1828, vol. II, p. 373, art. 10, frac. 5; p. 461, art. 265). Como se verá más adelante, no todas las cartas lo expresaron como fue el caso de la de Zacatecas.

El propósito de las siguientes líneas es explicar que el liberalismo tan acostumbrado a asociarse a la forma de gobierno federal (1824-1835), representó una continuidad durante la república central (1836-1846) al formular un catálogo de garantías individuales, al buscar el equilibrio constitucional con el diseño del Supremo Poder Conservador y al practicarse el derecho de petición por los ciudadanos. Se entiende por derecho de petición la solicitud presentada por escrito a la autoridad pública por los ciudadanos, para la observancia y cumplimiento de la Constitución ante lo que consideran un reclamo sobre un evento particular. La obligación de las autoridades es responder por escrito. Nuestra intención es mostrar que el ejercicio de ese derecho en el periodo centralista, entre otros factores, permitió abrir una nueva etapa en la cultura política mexicana: del republicanismo confederal al republicanismo federal, ${ }^{4}$ lo que implicó la transformación de las competencias administrativas entre las distintas esferas federal, estatal y municipal cuyo resultado fue un nuevo equilibrio. No es posible revalorar la experiencia de la república federal consagrada en la Constitución de 1857, sin reconocer el constitucionalismo de las décadas de 1830 y 1840 (Arroyo, 2011).

En este sentido, es fundamental comprender que a la constitución del Estado mexicano a través de diversas formas de gobierno, corrió parale-

En la caracterización propuesta por Carmagnani (1993, pp. 138-139) sobre las formas históricas del federalismo mexicano a lo largo de los siglos XIX y XX, el confederalismo del periodo 1824-1835 se manifestó por el predominio del poder político de las regiones a través de un fuerte apego a la defensa de la soberanía y un poder federal débil con escasas competencias. La tensión entre centralización-descentralización observada por el historiador se puso de manifiesto con gran fuerza entre las décadas de 1840 y 1850. El constitucionalismo de la década de 1840 apunta hacia la formulación de una nueva expresión del federalismo en el que el tema de las garantías constitucionales de los derechos individuales cobrará relevancia al constatar que las autoridades locales no los garantizan. Es hacia la década de 1850 en que la república, después de haber pasado por las experiencias confederal y unitaria, presentará una nueva correlación entre las autoridades federales y estatales, lo que da paso al federalismo liberal asociado con la defensa de las garantías individuales por parte de los poderes federales (Carmagnani, 2005, p. 16). 
lamente un proceso de formación y consolidación de una cultura política liberal que no se detuvo en los periodos en que el ideario centralista o monárquico impusieron sus expectativas. Por el contrario, las condiciones cambiantes de la política mexicana favorecieron la discusión y replanteamiento de las distintas experiencias de gobierno y sus referentes doctrinarios. Concretamente, el análisis de cómo algunas entidades mantuvieron un constante ejercicio de los instrumentos disponibles para consolidar la ciudadanía liberal y los derechos fundamentales garantizados en ella, muestran el intrincado proceso de entrenamiento político en los entornos regionales y locales; lleva la atención a las prácticas de negociación del poder local con el poder central y el peso de estas prácticas como elemento también constitutivo y normativo de los asuntos públicos más allá de las formas de gobierno instituidas en cada periodo.

\section{El liberalismo en la república central.}

\section{Algunas perspectivas historiográficas}

La historiografía contemporánea sobre las primeras décadas del orden republicano presenta interesantes ramas, donde destacan las contribuciones que confirman que el federalismo fue una expresión del liberalismo a través de la nueva cultura de la representación, el papel de sus funcionarios públicos en defensa de la constitución y de la soberanía, los nuevos contenidos en la enseñanza de la educación superior, la formación de la opinión pública, el método de elección de autoridades o la estructura y organización de la milicia cívica preparada para la defensa de su soberanía. En ese consenso historiográfico se ha considerado el peso de la tradición educativa y cultural de las intendencias como un antecedente fundamental: los catálogos bibliográficos de las distintas librerías conventuales muestran -hacia las últimas décadas del siglo XVIII y las primeras de la centuria siguiente- un creciente interés por los temas propios del mundo de la política como el constitucionalismo, el liberalismo, las formas de gobierno, la importancia del papel de los legisladores para templar las relaciones entre los pueblos, o títulos dedicados a los acontecimientos históricos como las revoluciones francesa, española o la independencia estadounidense.

En un estudio reciente dedicado al primer federalismo en Zacatecas (Vázquez, 2015), se hace hincapié en la capacidad de la administración pública estatal encabezada por el gobernador Francisco García Salinas (1829-1834) para impulsar proyectos de gran envergadura como: el fortalecimiento de la milicia cívica, el apoyo a la infraestructura para la industria minera junto con la creación de compañías controladas por el 
gobierno estatal, el establecimiento del Instituto Literario con la introducción de la cátedra de derecho civil, la iniciativa de crear un banco, el proyecto de la adquisición de grandes haciendas para repartirlas entre los labradores. Los estudios que han centrado su análisis en el federalismo en Zacatecas (Ríos, 2002; Rojas, 2010; Terán, 2015; Vega, 2006) coinciden en que se trató de una generación de políticos con sello liberal que tuvo capacidad de llegar a acuerdos para la implementación de políticas particulares que consolidaran su vocación autonómica mantenida desde las reformas borbónicas. Con diez años de federación, el estado de Zacatecas dio prueba de que aquella forma de gobierno era necesaria y conveniente para alcanzar "la felicidad de la nación". Liberalismo fue asociado con federalismo en la medida en que el poder regional se consolidaba y entraba en contradicción con un "arbitrario" poder central.

Con la interrupción del primer federalismo y la entrada en vigor de la república central en sus dos momentos -con las Siete Leyes de 1836 y las Bases Orgánicas publicadas en 1843- un acuerdo historiográfico heredado del modelo patriótico liberal explicó que el liberalismo también se había interrumpido al entrar en escena el conservadurismo mexicano. El gobernador zacatecano Francisco García Salinas sentenció en el último año de su gestión: "el pacto federal ha quedado disuelto". ${ }^{5}$ No era para menos con una serie de eventos que, desde la interpretación de los autoridades estatales, habían puesto en jaque al pacto federal como las elecciones presidenciales de 1828, el decreto de reducción de las milicias cívicas de 1835, el ataque a la defensa de la soberanía de las entidades, el rechazo a las reformas radicales del vicepresidente Valentín Gómez Farías de 1833.

La escritura de la historia política de la entidad, desde las versiones decimonónicas (Amador, 1892) hasta algunas de las contribuciones recientes (Candelas, 2010), considera que el centralismo fue un fracaso y constituyó un severo freno a la prosperidad de Zacatecas y de la República Mexicana. Fue un antiliberalismo traducido en la notoria disminución de la representación municipal; en la estructura autoritaria para designar al gobernador por parte del presidente de la república que sustituyó el papel que habían desempeñado los ayuntamientos al presentar terna al Congreso del estado; en la creación de un cuarto poder interpretado más como una imposición del ejecutivo, que como un regulador y árbitro de los otros tres poderes; en el carácter conservador de la nueva propuesta constitucional que chocaba con el discurso liberal de las autoridades lo-

5 AHEZ, Fondo reservado, "Memorias presentadas por Francisco García Salinas, gobernador del estado de Zacatecas al Congreso del mismo, en los años de 1829 a 1834". 
cales. El centralismo fue entendido como un freno al liberalismo; éste fue asociado exclusivamente con la forma de gobierno federal. Los años de centralismo representaron un incómodo paréntesis en la forja de la república liberal. Josefina Vázquez (1996) sostiene que gracias a las "verdades acuñadas por el liberalismo triunfante y las acusaciones de la retórica federalista", que asociaron centralismo con conservadurismo, se oscureció la labor del constitucionalismo vigente en las décadas de 1830 y 1840 como "el intento de los constituyentes de 1836 por reorganizar el sistema político para solucionar la crisis de la primera república federal" (p. 109).

Según la historiografía dedicada al tema en Zacatecas del siglo XIX, el liberalismo regresó en 1846 con el restablecimiento del sistema federal. Quizá por esa incomodidad que representa el centralismo tanto para la clase política como para la historiografía "liberal" no se le hubiera puesto atención y, en su lugar, pasara al olvido con una burda caracterización que hiciera en el siglo XIX el historiador decimonónico zacatecano: la república central significó el camino extraviado que conduciría a México, de manera inevitable, a su ruina (Amador, 1892).

El modelo patriótico liberal que asoció forma federal con liberalismo y república central con conservadurismo ha sido puesto en controversia por un conjunto de aportaciones (Andrews 2009a y 2009b, Arroyo 2011, Luna y Sordo 2012, Medina 2004, Sordo 1993, Vázquez 1987) que, por el contrario, ven a aquellas décadas como la búsqueda por el consenso de distintos grupos de políticos y letrados por encontrar la mejor forma de gobierno para la República.

Como se verá adelante, al estudiar el desarrollo de la cultura política zacatecana y su postura persistentemente soberanista, se podrá observar que las condiciones del gobierno centralista favorecieron hasta cierto punto un replanteamiento y eventual consolidación del liberalismo. En lugar de oponer en estancos separados a liberales versus conservadores, se han promovido estudios constitucionales (Andrews, 2009a, 2009b; Noriega, 1972), deteniéndose en las lecturas que hicieron los políticos mexicanos durante las décadas de 1820 y 1830, como el caso de las Reflexiones sobre la Revolución Francesa del irlandés Edmund Burke, quien planteara fuertes críticas a la tesis de la soberanía popular de Rousseau y en su lugar propusiera tomar distancia frente a la vorágine del avance de la Ilustración con el propósito de sopesar la experiencia histórica, revalorar la propia historia para sospechar de las utopías, considerar el orden preexistente para ser cautelosos con las seductoras ideas de libertad y soberanía popular. En esa línea de las lecturas que hicieron los políticos locales, destaca por su uso recurrente en la prensa, la correspondencia y los comunicados oficiales, la lectura del Curso de Política Constitucio- 
nal de Benjamin Constant que llegó a constituir una plataforma para el diseño constitucional en el tema del equilibrio de los poderes del Estado a partir de la incorporación de un poder neutro, capaz de representar la posibilidad de frenar los excesos como los que se habían manifestado en México, tanto con el poder legislativo como con el ejecutivo durante su primera experiencia federal (Pantoja, 2005).

El centralismo ha sido revalorado no como un antiliberalismo, sino como un nuevo camino por el que transitó el liberalismo mexicano. Notables estudios sobre el Congreso durante la república central (Sordo, 1993) han ayudado a desmontar viejas ideas que sostenían que aquella experiencia constitucional era propia de los militares y sacerdotes; el cambio de la forma de gobierno hacia la república central no se debió a una guerra intestina o a la voluntad de un general como Antonio López de Santa Anna, sino a la confluencia entre las representaciones de distintas corporaciones como pueblos y ayuntamientos, junto al peso que tuvieron los diputados pro centralistas, en particular en el Congreso general de 1835. Se ha avanzado en la crítica y superación de la visión trágica, caótica y violenta de las primeras décadas del siglo XIX, en su lugar, aquellas décadas se caracterizaron por la necesidad de constituir a la nación (Luna \& Sordo, 2012); "constituir" se volvió el verbo por antonomasia para definir la cultura política mexicana. Nuevos aportes sobre el constitucionalismo mexicano han puesto particular interés en el diseño de las Siete Leyes (Andrews, 2009a), contradiciendo la tesis del jurista Emilio Rabasa de que se trató de un "monstruo jurídico".

Desde esta perspectiva que busca deconstruir las versiones antinómicas de la historia nacional del siglo XIX, se considera que la supresión eventual del federalismo no afectó la "propuesta política medular del país" que siguió siendo republicana y liberal, en todo caso, las preocupaciones políticas del periodo siguieron vinculadas a definir la ciudadanía y frenar las prácticas corporativas tradicionales (Connaughton, 2010, pp. 13-15).

Una novedosa ruta interpretativa, a través del análisis de la interacción de códigos constitucionales y estado social (Arroyo, 2011), ha demostrado las continuidades entre la forma de gobierno federal y el diseño constitucional de las Siete Leyes de 1836. En contra de considerar a la constitución y leyes reglamentarias como una abstracción alejada de la sociedad y del marco "real", se explica que el plano normativo forma parte de esa realidad histórica. Uno de sus puntos de partida es que no hay formas de gobierno "puras", la experiencia histórica ha demostrado la imbricación de elementos inmediatos y lejanos en el diseño constitucional de las diversas experiencias mexicanas: "los constituyentes de los cuarenta no sólo fueron los 
padres del republicanismo federal e impulsores del liberalismo iusnaturalista en México, sino también idearon un pensamiento constitucional original que formó parte de Occidente" (Arroyo, 2011, p. 22).

Recuperando este conjunto de reflexiones historiográficas, para el estado de Zacatecas se realizó una investigación que dio cuenta de los vasos comunicantes entre la primera forma de gobierno federal y la central (Terán, 2015). Se consideró que las constituciones no pueden concebirse como un estanco apartado de la praxis política, y por más que se le haya caracterizado a las Siete Leyes como "monstruo jurídico" por haber golpeado el soberanismo de los estados, es indispensable detenerse en cada uno de sus artículos, en la reglamentación secundaria, en el discurso de los representantes de las autoridades departamentales, en la praxis política de individuos y corporaciones para contradecir la etiqueta de que centralismo es antiliberalismo.

\section{El golpe al soberanismo de Zacatecas}

Hacia 1834, al escenario político en la República Mexicana lo definían al menos tres tendencias: los que defendían la federación (con todo y los excesos de Valentín Gómez Farías), en particular algunas legislaturas como la zacatecana; los que pugnaban por la consolidación de un gobierno nacional (como lo advirtiera en su momento Servando Teresa de Mier, insistiera Lucas Alamán y definiera en un proyecto constitucional Francisco Manuel Sánchez de Tagle); y los que se aglutinaron en el Plan de Cuernavaca con una amplia convocatoria en múltiples pueblos de los estados de Tlaxcala, Puebla, Guanajuato, Veracruz, Morelos, Chihuahua, Campeche, Baja California, Oaxaca, Guerrero, Nayarit, Colima y el Estado de México, quienes sostenían la Constitución de 1824, la derogación de las reformas de 1833 de Valentín Gómez Farías, la conservación de la religión católica, la permanencia de los fueros militar y eclesiástico, la protección del general Antonio López de Santa Anna (Medina, 2004). El Plan de Cuernavaca, en mayo de 1834, hizo responsables a las legislaturas de la anarquía reinante: "Sumergida la república mexicana en el caos más espantoso de confusión y desorden a que la han sujetado las medidas violentas con que los cuerpos legislativos han llenado este periodo de sangre y lágrimas...". ${ }^{6}$ miento in Independent Mexico, 1821-1876. Arts \& Humanities Research Council. (s/f). Disponible en https://arts.st-andrews.ac.uk/pronunciamientos/dates. php?f=y\&pid $=1004 \& m=5 \& y=1834$ 
Ese contexto de tres tendencias permite observar no sólo las tensiones que se dieron entre algunos gobiernos estatales y el central por la pretensión de controlar la administración y las decisiones políticas sobre los territorios, sino la serie de competencias -que en ocasiones se volvieron conflicto- entre autoridades estatales (en particular las legislaturas) con los ayuntamientos. ${ }^{7}$ Estados como Zacatecas, con su discurso federalista, tuvieron hacia los municipios una práctica altamente centralizadora al grado que catorce ayuntamientos del estado encabezados por el de la capital, suscribieron representaciones críticas al federalismo y se declararon abiertamente por el establecimiento de una república central.

Hacia 1834 las críticas al federalismo arreciaron en la opinión pública en las representaciones de vecinos y ayuntamientos; esa forma de gobierno se había convertido en continuo choque de intereses entre centro y regiones, en la radicalización de las facciones, incompatibilidad de los liberales "demagogos" con la consecución del bien general, uso de interpretaciones contradictorias sobre la legislación nacional y las estatales, desobediencia y radicalismo de congresos estatales, falta de energía del ejecutivo federal y una hacienda pública debilitada.

Como se ha estudiado (Gómez, 2010; Sordo, 1993; Terán, 2015; Vázquez, 1993, 2015), Zacatecas fue la última pieza del territorio nacional por derrocar, que antecedió el diseño de una nueva expresión constitucional. La desobediencia que fomentó el gobernador Manuel González Cosío frente al decreto de reducción de milicias del 31 de marzo de 1835 y su desafiante actitud con el gobierno central, desbordaron cualquier intento de conciliar desacuerdos. La opinión pública no fue indulgente con Zacatecas, entre otros motes, se le llamó "aparato fanfarrón de poderes", "demagogia leperocrática" y "sultancillos"; su milicia cívica fue ridiculizada y el anterior gobernador, Francisco García Salinas, corrió con la misma suerte cuando se conoció que había sido nombrado comandante en jefe sabiendo que no conocía ni tenía la más mínima experiencia militar.

José María Gutiérrez de Estrada y José María Tornel expusieron las razones de su profundo desacuerdo con la posición de las autoridades zacatecanas: aquella entidad había usurpado funciones, sus pretensiones locales no tenían por qué llegar a ser legislación nacional. La manera en cómo Zacatecas había entendido el pacto federal no tenía que ser asumida por el conjunto de las entidades ni por el gobierno central; se había pasado al extremo de la subversión y desafío frente a los poderes nacionales. Mientras que Gutiérrez de Estrada señaló que quienes se habían

Esta contradicción fue analizada por Reynaldo Sordo (1993). 
desviado de la ley eran las autoridades de aquel estado y no los representantes de la nación, José María Tornel advirtió el "vértigo revolucionario en Zacatecas" causado por el decreto de reducción de las milicias del 31 de marzo de 1835. ¿De qué privilegios gozaba aquella entidad para tener un aparato militar como el que presumía, mientras el resto de las entidades no contaba con esa infraestructura militar? A diferencia de la opinión de Francisco García Salinas, José María Tornel sentenció que Zacatecas había roto el pacto federal al oponerse a una ley acordada por la representación nacional. El gobernador hizo un llamado a los milicianos para defender con las armas el pacto federal, la pretensión del gobierno central de invadir su territorio era una afrenta a un estado que había demostrado su apego al orden constitucional; Tornel insistió en que era una facultad del gobierno, "porque tiene la ciencia de su deber y de su poder", conservar el orden interno de la República: "ofenden altamente al gobierno supremo aplicándole el injurioso título de invasor". ${ }^{8}$

Una batalla ocurrida el 11 de mayo de 1835, en la que el general Antonio López de Santa Anna redujo sin mucho problema a la famosa y poderosa milicia zacatecana, representó el último episodio del protagónico papel que había desempeñado la entidad hasta entonces. De inmediato Zacatecas fue castigado con la aprobación por parte del Congreso general de independizar al boyante partido de Aguascalientes en ese mismo mes. Las razones de los integrantes del ayuntamiento de Aguascalientes por solicitar su separación se centraron en que la legislatura había frenado cualquier iniciativa de aquel partido para impulsar su prosperidad atentando contra sus derechos y libertades. En una extensa representación dirigida al Congreso expusieron que esa fama liberal de Zacatecas nada tenía que ver con el trato despótico que habían recibido los municipios por parte de las autoridades del estado, quienes habían ejercido el poder de manera arbitraria. Recordaron que desde la legislación española el ayuntamiento tenía un lugar preponderante; si la idea del bien común de los pueblos fue alentada en tiempos de la monarquía, cómo podía ser con- 
traria en tiempos de la república; los ayuntamientos no podían reducirse a ser "esclavos bien vestidos":

La general propensión que se advierte en todo supremo poder constitucional de deprimir y sujetar al local, situándolo en una rigurosa y servil dependencia; sin que se sepa, como dice uno de los modernos políticos citados (B. Constant) por qué se le tema, se le deprima y sujete, cuando todo lo contrario convendría hacer. Dejando obrar en libertad al poder local y protegiéndolo, estarían sin duda mejor gobernados en su interior los pueblos y del arreglo de esas secciones o pequeñas familias, de que se compone la gran familia del estado, resultaría el mejor gobierno total de éste. ${ }^{9}$

El caso de la separación del partido de Aguascalientes respecto del estado de Zacatecas permite observar dos procesos: por una parte las autoridades de Zacatecas demostraron capacidad de establecer coaliciones con otras entidades valiéndose de la eficacia del discurso político federalista en torno a la defensa de su soberanía, de la constitución y del pacto federal, pero con un ejercicio del poder centralizado que subestimó la tradición municipalista; por otro lado, la serie de representaciones de los ayuntamientos que se pronunciaron por la república central a lo largo de 1834, evidenciaron los conflictos de interés con la pretendida jerarquía política de las legislaturas.

Unos cuantos días después de que se aprobara la separación del partido de Aguascalientes, los integrantes del ayuntamiento de Zacatecas redactaron otra representación dirigida al Congreso general en la que se hacía alusión a desórdenes, vejaciones y opresiones ocurridos desde 1824 debidos al sistema federal; pedían al Congreso obviar el artículo 171 de la Constitución de 1824 para convertirse en convocante.

Si en 1823 Servando Teresa de Mier había anticipado los riesgos de establecer un federalismo radical, en 1834 Lucas Alamán publicó su "Examen imparcial" en donde hizo una aguda crítica al proceso constitucional mexicano que adoptó "de manera servil" la Constitución española de 1812. El problema de origen radicaba en el diseño constitucional con el desequilibrio de los poderes; el ejercicio de la autoridad debía emanar de un centro rector que diluyera los amplios márgenes de los poderes regionales preexistentes en la República. Aguascalientes, sobre separarse del estado de Zacatecas, erigiéndose en territorio. Representación de los mismos al congreso de la unión y resolución de éste". 
Los estados del México central pugnaron por diseñar una nueva constitución; en Zacatecas se propuso la reforma constitucional. Los argumentos para establecer un nuevo constituyente radicaron en que la experiencia podía ser un elemento de gran valor para mejorar las constituciones; once años de forma de gobierno federal eran suficientes para reconocer excesos y establecer nuevos límites en un código constitucional que fuera producto de una reflexión madura, donde práctica y ley condensaran una posibilidad para garantizar una mejor organización de la sociedad mexicana. Ejemplos los habían dado otras naciones. El ayuntamiento de Guadalajara, en el estado de Jalisco, hizo referencia al derecho indisputable de los pueblos de constituirse nuevamente. Para justificar otro diseño constitucional, Francisco Manuel Sánchez de Tagle formuló argumentos semejantes a los que apuntara fray Servando en 1823: los mexicanos no estaban preparados para una rápida transición; la independencia no podía cortar las costumbres, instituciones y organización prevalecientes por siglos; el proceso de tránsito debía ser gradual: "elegimos el hermoso sistema federal, el más a propósito para ese estado [...] pero quizá poco adecuado a nuestra situación de entonces y difícilmente acomodable a nuestras costumbres, educación y propensiones de aquel tiempo". ${ }^{10}$

Los críticos del centralismo pusieron atención en que las Siete Leyes redujeron drásticamente la representación municipal al reconocer al municipio con una base de 8000 habitantes, al anular la soberanía de los estados convirtiéndolos en departamentos, al excluir de los procesos electorales a todo aquel que no demostrara propiedad y al crear un cuarto poder conservador inútil y arbitrario. Alfonso Noriega (1972) sostiene, por el contrario, que las Siete Leyes representaron una innovación al declarar la existencia de garantías individuales en la primera de sus leyes, al poner límites no sólo al legislativo, sino también al ejecutivo con la creación de un cuarto poder para lograr el control de la constitucionalidad. La pretensión por crear el Supremo Poder Conservador venía en gran parte de la valoración de la experiencia federal reciente que probó su estado fluctuante en donde las acciones de las nocivas revoluciones justificadas con la pretendida "voluntad popular" demostraron estar por encima del código constitucional. Para Sánchez de Tagle (1835), el Poder Conservador tendría la misma lógica que el movimiento físico de los cuerpos, no era activo en sí mismo, sino detendría la acción de los otros,

“Contestación del Sr. Francisco Manuel Sánchez de Tagle, presidente de la cámara de diputados, al presidente interino de la república, Miguel Barragán", 10 de julio de 1835 (21 de julio de 1835). Diario del Gobierno de los Estados Unidos Mexicanos. 
los resistiría; pero ¿qué necesidad de ese poder si en los otros poderes están los hombres buenos? El político respondió: "para que no dejen de serlo".

\section{Los abusos de autoridad y el ejercicio del derecho de petición}

El 5 de noviembre de 1835 el secretario interino del gobierno de Zacatecas dio lectura a las Bases Constitucionales en presencia del gobernador, Santiago Villegas y de los integrantes de la junta departamental: se detuvo en las atribuciones y límites de los nuevos funcionarios. Los presentes rindieron juramento y pasaron a la Iglesia mayor a dar gracias al todopoderoso por el nuevo orden. Protocolo similar se dio en otras municipalidades a cargo del jefe político. En 1837 las corporaciones que habían realizado el juramento y no cumplieron con el requisito del artículo 22 de la Sexta Ley relativo al número de 8000 habitantes para contar con ayuntamiento fueron disueltas en su condición de municipios integrándose a otras cabeceras.

El nuevo orden fue un fuerte descalabro para la representación municipal tomando en consideración el peso y ritmo que el liberalismo gaditano habían marcado con la proliferación de ayuntamientos; sin embargo, a través de mecanismos no necesariamente previstos por las Leyes Constitucionales de 1836, se retomaron antiguos preceptos constitucionales ejercidos por medio de prácticas políticas que ayudaron a conformar un derecho de los ciudadanos que supieron interpretar los vocales de la junta departamental y los diputados ante el congreso general: el derecho de petición formulado justamente como una reacción ante la nueva composición de la estructura del poder ejecutivo en el nivel departamental establecida en el código de 1836 y en la reglamentación particular para el gobierno interior de los departamentos.

Para observar en el plano de la representación política la conformación del derecho de petición durante la república central, consideramos dos dimensiones: el conjunto de acciones encabezadas por los vecinos de distintas comunidades del departamento de Zacatecas y las observaciones que realizaron tanto el diputado Pedro Ramírez ante el congreso general en 1841, como los vocales de la junta departamental respecto de las Bases Orgánicas de 1843.

Las autoridades unipersonales como el jefe político, representaron una franca competencia con los ayuntamientos que lograron sobrevivir al artículo 22 de la Sexta Ley. En el caso de Zacatecas, la figura del jefe político se introdujo durante el gobierno de Francisco García Salinas con la Constitución de 1832, no como cargo de elección popular, sino desig- 
nado por el gobernador. El jefe político sería nombrado por el ejecutivo a propuesta en terna de los ayuntamientos y juntas municipales. ${ }^{11}$

Más tarde sus funciones se especificaron en el "Reglamento de gobierno interior de los departamentos" de marzo de 1837; designados por el gobernador y confirmados por el gobierno general, podían ocupar el cargo en cada uno de los partidos del departamento de manera indefinida. El jefe político se constituyó en el brazo derecho del gobernador para garantizar el cumplimiento de sus atribuciones. Entre sus funciones se encargó de vigilar y sobrevigilar la administración de los bienes municipales, si los ayuntamientos celebraban contratos, cesiones o donaciones sin su supervisión y aprobación, se considerarían sin ningún valor. ${ }^{12}$

La manera en que se dio a conocer la nueva forma de gobierno republicana central a las corporaciones por los jefes políticos fue simbólica. El del partido de Zacatecas, en sesión especial, dio noticia al ayuntamiento de la ciudad de las adhesiones que otros municipios de la otrora entidad federal habían expresado a favor de la república central; ellos fueron los encargados de hacer circular los ejemplares de las Leyes Constitucionales y dar lectura en presencia de los principales funcionarios y corporaciones civiles y religiosas.

El nivel de injerencia de los jefes políticos en los temas de conocimiento de los registros de la población, seguridad, orden, protección, salud, educación, cultura cívica, sanidad, finanzas municipales y nombramiento de jueces de paz, permitió que el gobernador pudiera asomarse y hacer presente su poder en los lugares más alejados del departamento. El ayuntamiento de Aguascalientes lo etiquetó como "celador importuno"; sin embargo, también gozó de reconocimiento y legitimidad. Su consejo fue solicitado por las propias corporaciones municipales, como la de Guadalupe, frente a situaciones en donde sentían ultrajado su honor por las expresiones violentas de alguno de los vecinos; en otras ocasiones se le pidió interviniera para nombrar al juez de paz o exigir la presencia inmediata del depositario de cuentas del ayuntamiento para su glosa y aprobación. ${ }^{13}$

11 administración", 28 de abril de 1842, fondo Ayuntamiento de Zacatecas, serie Actas de cabildo, subserie Correspondencia. 
Según la documentación revisada, los jefes políticos se tomaron muy en serio su papel, sobre todo en lo relativo al reclutamiento y vigilancia de los vagos y malentretenidos. Dicha función fue objeto de confusión de competencias entre autoridades locales, pues en el Reglamento del Gobierno Interior de los Departamentos del 20 de marzo de 1837, una de las atribuciones de los ayuntamientos era la de procurar la seguridad, protección y policía persiguiendo "a la gente viciosa, holgazana y malentretenida". En el artículo 69 del mismo reglamento se establecía una idea similar otorgando al jefe político la facultad de destinar a vagos y ociosos a establecimientos como obrajes o haciendas de labor; en los artículos 169 al 172, sería atribución de los alcaldes perseguir a los malhechores y conservar el orden público, imponer multas, arrestos o días de trabajo en obras públicas a los que perturbaran la tranquilidad. ${ }^{14} \mathrm{La}$ reglamentación secundaria en los temas de policía y conservación del orden contribuyó a la confusión de atribuciones entre ayuntamientos y jefes políticos. ${ }^{15}$

El diseño de un nuevo Reglamento para la Policía del Gobierno Interior de los pueblos del Departamento en 1839 pretendió eliminar las ambigüedades en la cuestión, pues el destino de los vagos y malhechores quedó en manos del jefe político, quien valiéndose de nombramientos de comisarios y jueces logró incrementar el número de reclutas.

La reglamentación particular para la conservación del orden durante el centralismo desencadenó un conjunto de tensiones entre ciudadanos y funcionarios quienes, como el jefe político, se habían tomado muy en serio su papel. Los reclamos y exigencias elaborados a través de una representación escrita de los ciudadanos agraviados por el abuso de autoridad de este funcionario se acumularon en la mesa de la junta departamental. Este tipo de acciones fueron conformando desde su práctica política, el derecho de petición con lo que el liberalismo no era un asunto que se hubiera quedado en el pasado inmediato de la república federal.

Si bien el derecho de petición no estuvo contemplado en la Constitución Federal de los Estados Unidos Mexicanos de 1824, ni en las constituciones particulares de Zacatecas de 1825 y 1832, respondía a una larga tradición: ${ }^{16}$ "este precepto consuetudinario provenía del tiempo

\begin{tabular}{l|l}
14 & AHEZ, "Reglamento del gobierno interior de los Departamentos", 20 de marzo de 1837, \\
fondo Poder legislativo, serie Leyes, decretos y reglamentos. \\
El artículo 79 establecía que los ayuntamientos tendrían la facultad, a través de los \\
alcaldes, de recibir información en donde se comprobara el mal modo de vivir y la \\
ociosidad de todo aquel que perjudicara las buenas costumbres. Los podrían destinar a \\
ocho días y si reincidiesen, se multiplicarían los días de trabajo en obras públicas. \\
${ }_{16}$
\end{tabular} 
colonial y se utilizó por varios siglos con la denominación genérica de representación" (Arroyo, 2011, p. 184). Beatriz Rojas (2015), señala para el muy poco atendido derecho de petición, que "la representación como demanda de justicia fue uno de los recursos más utilizados en el antiguo régimen" (p. 2). Se ha considerado que su primera formulación constitucional fue hasta 1857, ${ }^{17}$ olvidando sus antecedentes en la Constitución Política de la Monarquía Española de 1812 en su artículo $373^{18}$ y en el artículo 27 del Decreto para la Libertad de la América Mexicana de 1814 (Rojas, 2015). ${ }^{19}$ Por su parte, en 1821, entre los integrantes de la Junta Suprema Provisional Nacional Gubernativa, se expuso su importancia recordando la tradición pactista entre el soberano y los pueblos, donde aquél tenía la obligación de escuchar las quejas y peticiones de éstos en tanto fuesen justas.

XVII, en Bill of Rigths del 13 de febrero de 1689: "Que es derecho del ciudadano dirigir una petición al rey, y que todo encarcelamiento y enjuiciamiento como consecuencia de esa petición son ilegítimos". El siguiente documento que incorpora el derecho de petición fue la "Declaración de derechos del hombre y del ciudadano" del 24 de junio de 1793: "el derecho de presentar peticiones a los depositarios de la autoridad pública no puede ser, en ningún caso, prohibido, suspendido o limitado". En la Novísima Recopilación también se toma como uno de sus antecedentes: "liberal se debe mostrar el rey en oír peticiones y querellas a todos los que a su corte vinieren a pedir justicia" (Cienfuegos, 2004). Por lo que se refiere al constitucionalismo moderno, el autor no menciona el derecho de petición en la Constitución Política de la Monarquía Española de 1812, aunque sí en el Decreto para la América Mexicana de 1814. Véase el artículo citado de Beatriz Rojas (2015): al referir la práctica de las representaciones en el antiguo régimen, la historiadora afirma que "aunque tardó varios decenios en integrarse a la Constitución, no dejó de recurrir a ella para manifestar ante las autoridades una petición o un reclamo. Su vigencia no se puso en duda, aunque no se haya constitucionalizado o legislado sobre ella sino hasta mediados de siglo". Artículo 373: "Todo español tiene derecho a representar a las Cortes o al Rey para reclamar la observancia de la Constitución", Constitución Política de la Monarquía Española, 1812 (Rojas, 2015). Para confirmar que el derecho de petición no fue contemplado en la Constitución de 1812, Beatriz Rojas (2015), cita al jurista mexicano Isidro Antonio Montiel y Duarte, quien escribiera en 1873: "La constitución española nada absolutamente dice acerca del derecho de petición, y sin embargo es un hecho que a nadie se estorbó ni se pudo estorbar que formulara sus pretensiones en materias legislativa o administrativa..."

Artículo 37: "A ningún ciudadano debe coartarse la libertad de declarar su derechos ante funcionarios de la autoridad pública", Decreto Constitucional para la Libertad de la América Mexicana, 1814 (Rojas, 2015). 
La constitucionalización del derecho de petición se había formulado durante la primera república federal en el nivel estatal. En algunas de las constituciones de las nuevas entidades quedó formalmente declarado:

Constitución del Estado de Occidente:

Todo sonorense puede reclamar la observancia de esta Constitución y denunciar directamente al congreso las infracciones que se cometan por los tribunales y funcionarios del estado, con tal que lo haga con moderación. De la misma manera representará cada y cuando convenga, por el orden de las leyes, a la legislatura, al gobierno o a cualquiera otra autoridad pública, sus individuales derechos, siendo responsable de sus escritos. (Galván, 1828, Tomo III, artículos 22-23, p. 9).

Constitución de Yucatán:

Todos tienen un mismo derecho para pedir libre y moderadamente ante los depositarios de la autoridad pública la observancia de esta Constitución y el cumplimiento de las leyes (Galván, 1828, Tomo III, p. 335).

Constitución de Tamaulipas:

Todo habitante del estado tiene derecho para pedir a la legislatura la corrección de las infracciones que note, y a obtener la reparación de los obstáculos que le embaracen en el ejercicio de sus derechos, con tal que lo haga con tranquilidad y decencia. Estas reparaciones no pueden diferirse arbitrariamente, ni rehusarse (Galván, 1828, Tomo III, p. 169).

Constitución de Oaxaca:

Los derechos civiles de los oaxaqueños que se les garantizan por esta Constitución son: la libertad individual y seguridad personal, la libertad de imprenta, el derecho de propiedad, la igualdad ante la ley, el derecho de petición y el derecho de ser gobernados por la constitución y leyes que sean conformes con ella (Galván, 1828, Tomo II, p. 168).

Constitución de Querétaro:

Garantiza igualmente a los ciudadanos queretanos el derecho de petición, cuyo uso se arreglará por una ley (Galván, 1828, Tomo II, p. 298).

Constitución de San Luis Potosí: relativo a las obligaciones del Estado y deberes de los habitantes, "El derecho de petición según el uso que conceda la ley" (Galván, 1828, Tomo II, p. 372). 
Durante la república central se acumularon expedientes en donde no fueron precisamente las corporaciones a través de representaciones, sino los vecinos en lo individual, por medio de escritos, quienes solicitaron a las autoridades departamentales (la junta o la asamblea legislativa) su intervención a propósito de los numerosos casos de abuso de autoridad de los jefes políticos o subprefectos.

Es interesante resaltar que en las décadas de 1830 y 1840 los pronunciamientos, actas y planes habían sido una de las prácticas más socorridas de corporaciones como pueblos, guarniciones o ayuntamientos para exigir derechos o expresar su rechazo o adhesión hacia alguna forma de gobierno. Se trató de un tipo de acción política de las corporaciones, pero en estricto sentido, no pueden ubicarse en el derecho de petición, dadas sus características jurídicas establecidas en los diferentes códigos constitucionales, donde se prescribió que para su ejercicio debía cumplirse con el requisito de formularse por escrito, dirigido a una autoridad competente y esperar su respuesta.

Las solicitudes remitidas para pedir la intervención de las autoridades departamentales contra los agravios cometidos por autoridades unipersonales representaron un recurso para evitar hacer justicia por propia mano. El ejercicio de este conjunto de peticiones enarbolaron la salvaguarda de otro tipo de derechos, como el de la libertad, la propiedad o el libre tránsito.

Los abusos de autoridad fueron reclamados por los ciudadanos en lo individual, a través de un documento escrito ante la junta departamental. Los agraviados exponían a las autoridades la serie de eventos en que consideraban se habían vulnerados sus derechos; se trató de un mecanismo concreto entre gobernantes y gobernados para exigir justicia.

La principal queja que presentaron los ciudadanos de distintas comunidades ante la junta departamental fue por abuso de autoridad de los jefes políticos y subprefectos: porque alteraban los juicios, detenían más tiempo del debido a los reos, arrestaban de manera injustificada, exigían cobros indebidos, maltrataban de obra y palabra a los presos y los obligaban a realizar servicios en sus propiedades. Fueron comunes los casos de arrestos arbitrarios, como el de uno de los vecinos del mineral de Vetagrande, quien en su reclamo ante la junta departamental expuso:

Cuando he visto que sin haber podido recabar orden alguna contra mí de la suya, me ha reducido a prisión, ejerciendo una facultad tan digna, tan honrosa y severa, propia sólo de la autoridad, de la probidad y de la justicia, me ha desesperado al ver que la calificación de 
si un hombre debe ser preso o, lo que es lo mismo, de si debe gozar o no de libertad, de si debe privarse o no de consideración, la hace por desgracia en Zacatecas un facineroso marcado por la opinión pública con distintas causas pendientes y sin los elementos siquiera de una educación culta para poder juzgar de los hombres sin atropellar la moral y la civilización. ${ }^{20}$

Por ejemplo, los vecinos de Jalpa manifestaron en 1839 que no tenían garantías que los protegieran por reclamar ante la junta departamental el abuso de autoridad del subprefecto, quien conociendo de los hechos, actuaría en venganza contra ellos. Esta situación en particular hizo recordar a la comisión nombrada por junta, el decreto emitido por las Cortes de Cádiz el 24 de marzo de 1813, donde se determinaba que "un jefe político acusado no pudiese estar en el pueblo en que debiese practicar la información sumaria, ni en seis leguas en su entorno" ${ }^{21}$ Los vocales recordaron el decreto, pero expusieron que ya no tenía vigencia, en cambio podían considerar la fracción 5 del artículo 7 de la Sexta Ley que establecía la facultad del gobernador para la "suspensión temporal y aun privación de una parte de sus sueldos a los empleados públicos".

Los expedientes en esta materia se multiplicaron entre 1837 y 1841 a tal grado que en el dictamen de la junta departamental de Zacatecas sobre las reformas a la Constitución, los vocales se manifestaron no por el cambio en la forma de gobierno, sino por la exigencia de contar con mayor autonomía y libertad para la organización y administración de la vida pública del departamento. El dictamen dio cuenta de las coincidencias con las juntas departamentales de Guanajuato y Sonora y con el propio diputado ante el congreso general, el licenciado Pedro Ramírez. El discurso de los vocales zacatecanos pugnaba por una reforma que evidenciara el "manifiesto y universal odio contra la Constitución de 1836". En su opinión los males se habían radicalizado con la pérdida de derechos como el de elegir a sus gobernantes, el cierre de varios tribunales debido a la carencia de recursos para su conservación, la privación de la protección militar que habían gozado en el federalismo; ahora tenían una república desarmada por la pérdida del territorio nacional "nuestros enemigos nos han puesto de escabel de sus pies"; los males de la república se debían

\footnotetext{
20 "Queja del preso Lázaro Hernández contra el prefecto de la capital de Zacatecas por abuso de autoridad". AHEZ, 27 de abril de 1841, fondo Poder Legislativo, serie Gobierno.

21 "Queja de un vecino de Jalpa por abuso de autoridad del subprefecto". AHEZ, 18 de julio de 1839, fondo Poder Legislativo, serie Gobierno.
} 
en gran parte "a la bastardía de los orígenes" de aquella Constitución (Vázquez, 1987, p. 29). ${ }^{22}$

En un largo dictamen, los vocales de la junta departamental de Zacatecas expusieron sus criterios y argumentos de dónde y por qué debía reformarse la Constitución de 1836: el derecho de petición encabezó la lista, circunscrito al derecho que todo mexicano debía tener para presentar por escrito iniciativas al congreso general o juntas departamentales "sobre aquellos objetos que parezcan de necesidad o utilidad pública". El argumento era la conservación de la sociedad política y la garantía del bien común; no se les podía privar de su derecho para que en el momento en que lo juzgasen necesario, reclamasen todo aquello que tendiera al goce de sus derechos naturales:

¿Con qué razón, con qué justicia se les priva de promover directamente lo que juzguen necesario para lograr aquel fin? ¿o por qué se les concede como una gracia y con las trabas y restricciones que se advierten en el proyecto? A la verdad es una inconsecuencia cargar a los mexicanos con todas las obligaciones sociales y quitarles la facultad de que promuevan, por medio de iniciativas, lo que crean conveniente para la felicidad procomunal. Parece, pues, indispensable pedir, que entre el catálogo de los derechos del mexicano, se comprenda el de poder hacer iniciativas y peticiones sobre cualquier materia al congreso y a las juntas departamentales. (Vázquez, 1987, p. 29)

No podía disociarse el derecho de petición que presentaron los zacatecanos ante el Congreso general, con el derecho a la libertad individual que también defendieron en el mismo dictamen; la reforma debía descansar en este principio como uno de sus principales basamentos. Citaron a Montesquieu para afianzar su posición: la libertad política no podía lograrse con el sacrificio de la libertad individual, los hombres deben tener el derecho a no estar sometidos más que a la ley; esa fue su posición, por tanto, no podían ser detenidos, presos, privados de su vida, maltratados por la voluntad arbitraria de cualquier funcionario. El derecho a la libertad individual debía proteger a los ciudadanos de su decir, pedir y opinar, disponer su tiempo, escoger su industria, disponer de su propiedad, transitar en donde conviniese sin permiso ni obligación de dar cuenta de cada uno de sus pasos, reunirse y asociarse con otros, es:

22 "Dictamen de la Junta Departamental de Zacatecas sobre reformas a la Constitución, fue el más detallado y largo (1841)", p. 29. 
El derecho de influir en la administración del gobierno o en el nombramiento de algunos o de todos los funcionarios, sea por representaciones, por peticiones o por consultas que la autoridad está más o menos obligada a tomar en consideración. A la comisión le parece que éstos y no otros, son los fundamentos de una buena constitución (Vázquez, 1987, p. 31).

En el ambiente político constitucional, la exigencia de algunos representantes ante el congreso general para integrar el derecho de petición -cuya naturaleza implicaba la noción de la representación individual del ciudadano- constituyó uno de sus principales reclamos. La junta departamental de Zacatecas y el diputado Pedro Ramírez insistieron en su inclusión como una manera de garantizar los derechos del ciudadano. Sin embargo, José María Gutiérrez de Estrada se adelantó en 1835 al presentar su "Proyecto de ley para el arreglo del derecho de petición" ante la ola de pronunciamientos desatados en distintas partes de la República en donde las corporaciones expresaban su reclamo a través de un representante. Israel Arroyo (2011) destaca la iniciativa de Gutiérrez de Estrada como un antecedente clave para el reformismo de la década de 1840. Entre su articulado, cita el segundo que muestra la condición que ese derecho debía tener: su carácter individual e intransferible en contraposición a la práctica política del pronunciamiento de naturaleza colectiva:

El derecho de petición es individual y no puede delegarse. En consecuencia, no puede ser ejercido bajo un nombre colectivo por los cuerpos electorales, judiciarios, administrativos, municipales, ni por las reuniones de ciudadanos de cualquier especie que sean (p. 143).

El constitucionalismo de la década de 1840 permite asociar el derecho de petición con el juicio de amparo. El proyecto constitucional de 1842 estableció en su artículo 150 el derecho que tienen los ciudadanos de interponer recurso para reclamar ante la Suprema Corte de Justicia contra los actos de autoridades departamentales por la violación a alguna de las garantías constitucionales. Por su parte, en el artículo 118 fracción XII de las Bases Orgánicas de 1843, se consideró como facultad de la Alta Corte "conocer de los recursos de nulidad que se interpongan contra las sentencias dadas en última instancia por los tribunales superiores de los Departamentos". ${ }^{23}$ Ambos textos hacen referencia a un mecanismo concreto a través del derecho que tuvieron los ciudadanos para asegurar el control de la constitucionalidad a través del poder judicial. En 1840, Ma-

$23 \mid \begin{aligned} & \text { Bases Orgánicas de la República Mexicana, } 14 \text { de junio de 1843, Artículo } 118 \text { “De las } \\ & \text { facultades de la Corte Suprema de Justicia”, fracción XII. }\end{aligned}$ 
nuel Crescencio García Rejón en su proyecto de Constitución de Yucatán, justificó la inclusión del juicio de amparo como derecho de los ciudadanos contra los actos del legislativo, del ejecutivo o de cualquier otra autoridad considerados inconstitucionales (Soberanes, 1998, p. 649). El juicio de amparo es un signo de una nueva formulación del federalismo mexicano propuesto desde la república central en donde los ciudadanos en lo individual solicitarían la intervención del poder judicial de la federación para contener los actos de autoridad de diputados, gobernadores y magistrados; hay una liga entre el derecho de petición y el juicio de amparo: se trata de un derecho ejercido de manera individual e intransferible para reclamar la violación a garantías constitucionales ante actos ejercidos por autoridad pública y evitar hacer justicia por sí mismo.

\section{Consideraciones finales}

El tema del derecho de petición fue planteado por Mariano Otero para la redacción del Acta de Reforma de 1847:

A mi juicio, en la Constitución, después de fijar la base, sólo deben determinarse las prerrogativas inherentes a esa cualidad, y el artículo 2 que yo propongo, establece que el derecho de ciudadanía trae consigo el de votar en las elecciones populares, el de ejercer el de petición, el de reunirse para discutir los negocios públicos y, finalmente, el de pertenecer a la Guardia Nacional, todo conforme a las leyes (Cienfuegos, 2004, p. 8).

El derecho de petición quedó establecido en el Acta de Reformas de $1847 ; 24$ en el proyecto de 1856 se definió su carácter inviolable y la facultad de su ejercicio por los ciudadanos de la república. Quedó establecido en el artículo 8 de la Constitución de 1857:

Es inviolable el derecho de petición ejercido por escrito de una manera pacífica y respetuosa; pero en materias políticas solo pueden ejercerlo los ciudadanos de la república. A toda petición debe recaer acuerdo escrito de la autoridad a quien se haya dirigido, y ésta tiene obligación de hacer conocer el resultado al peticionario. ${ }^{25}$

24

25

Acta de Reformas, 1847, Artículo 2: "Es derecho de los ciudadanos votar en las elecciones populares, ejercer el de petición, reunirse para discutir los negocios públicos y pertenecer a la Guardia Nacional, todo conforme a las leyes".

Constitución Política de la República Mexicana, 1857. Título I, Sección I "De los derechos del hombre", Artículo 8. 
Claramente el derecho de petición poseía un largo antecedente fincado tanto en la tradición antigua como en el constitucionalismo a partir de 1812. Lo importante a destacar entonces sería cómo a través del derecho de petición, ya concebido como garantía constitucional, se puede observar el aprendizaje de la condición ciudadana y las transformaciones en la ejecución de este derecho, como herramienta para apelar a la gracia de un poder condescendiente, a un empleo ciudadanizado para negociar con espacios modernos de interpelación. Al atender el ejercicio del derecho de petición, se puede observar cómo los sujetos fueron apropiándose y ejercitando las concepciones del Estado moderno. Se midieron de este modo los límites de la división de poderes, su estructura y sus prácticas con especial interés en los ámbitos locales. Es pues una pista fundamental para comprender el complejo tránsito de las prácticas políticas del antiguo régimen hacia la cultura liberal.

La condena que se hizo a las Siete Leyes de conservadora, antiliberal y fracasada sobre todo por sus segunda y sexta leyes, ocultó que en esos años se fue formulando una nueva relación entre los gobernados en su calidad de individuos y las autoridades departamentales a través de la serie de peticiones por escrito que se le hicieron sobre los abusos de autoridad cometidos por funcionarios como los jefes políticos y subprefectos. En el marco de la república central se fue dando la promoción de una república liberal y moderna que fue perfilando una nueva posición del individuo respecto de las autoridades. Esto le resta peso a las interpretaciones que en su tiempo y ahora sostienen que el centralismo es un antiliberalismo. El liberalismo fue propio del confederalismo, del centralismo, de la monarquía constitucional. El liberalismo constitucional representó no sólo la fe en las constituciones, se trató de una efectiva implementación institucional y por diversos actores para la formulación de nuevas bases como el catálogo de garantías individuales, la creación del derecho de amparo, la pretensión por lograr el control de la constitucionalidad y la insistencia por considerar al derecho de petición en el código constitucional.

\section{Archivos}

AHEZ Archivo Histórico del Estado de Zacatecas.

BPB-ATV Biblioteca Pública del Bicentenario, Colección Alejandro Topete del Valle.

\section{Referencias bibliográficas}

Acta constitutiva y de reformas sancionada por el Congreso Extraodinario Constituyente de los Estados Unidos Mexicanos (1847). Disponible en: http://www.ordenjuridico.gob.mx/Constitucion/1847.pdf 
Amador, E. (1892)

Bosquejo histórico de Zacatecas (Tomo II). Zacatecas: Reimpreso por el Supremo Gobierno del Estado de Zacatecas.

Andrews, C. (2009a)

El debate político de la década de 1830 y los orígenes de las Siete Leyes. En C. Noriega \& A. Salmerón (Coords.), México: un siglo de historia constitucional (1808-1917). México: Suprema Corte de Justicia de la Nación/Instituto Mora.

Andrews, C. (2009b)

Sobre conservadurismo e ideas conservadoras en la primera república federal (1824-1835). En E. Pani (Coord.), Conservadurismo y derechas en la historia de México (Tomo I, pp. 86-134). México: Fondo de Cultura Económica/Consejo Nacional para la Cultura y las Artes.

Arroyo, I. (2011)

La arquitectura del Estado mexicano: formas de gobierno, representación política y ciudadanía, 1821-1857. México: Instituto Mora/ Benemérita Universidad Autónoma de Puebla.

Acta del pronunciamiento de Cuernavaca, 25 de mayo de 1834. The Pronunciamiento in Independent Mexico, 1821-1876. Arts \& Humanities Research Council. (s/f). Disponible en https://arts.st-andrews.ac.uk/ pronunciamientos/dates.php?f=y\&pid=1004\&m=5\&y=1834

Candelas, S. (2010)

Los anales de García (1786-1841). México: Miguel Ángel Porrúa.

Carmagnani, M. (1993)

El federalismo liberal mexicano. Federalismos latinoamericanos. México, Brasil, Argentina (pp. 135-179). México: Fondo de Cultura Económica/El Colegio de México/Fideicomiso Historia de las Américas.

Carmagnani, M. (2005)

Las formas del federalismo mexicano. Lecciones sobre federalismo. Zacatecas: Universidad Autónoma de Zacatecas/Consejo Nacional de Ciencia y Tecnología.

Cienfuegos, D. (2004)

El derecho de petición en México (Serie Doctrina Jurídica, núm. 182).

México: Universidad Nacional Autónoma de México.

Connaughton, B. (2010)

Entre la voz de Dios y el llamado de la patria. México: Fondo de Cultura Económica.

Constitución Política de la República Mexicana, 1857.

Galván, M. (1828)

Colección de constituciones de los Estados Unidos Mexicanos (3 volúmenes). México: Imprenta de Galván a cargo de Mariano Arévalo. 
Gómez, J. (2010)

La creación del departamento de Aguascalientes en el contexto del enfrentamiento con Zacatecas contra el gobierno federal. En A. Hernández \& M. Terán (Coords.), Federalismo, ciudadanía y representación (pp. 341-364). Zacatecas: Universidad Autónoma de Zacatecas/ Consejo Nacional de Ciencia y Tecnología.

Luna, A. \& Sordo, R. (2012)

La vida política. En M. Luna (Coord.), México: la construcción nacional (Serie América Latina en la Historia Contemporánea, tomo 2, pp. 3385). Madrid: Fundación MAPFRE.

Medina, L. (2004)

Invención del sistema político mexicano. Formas de gobierno y gobernabilidad en México en el siglo XIX. México: Fondo de Cultura Económica.

Noriega, A. (1972)

El pensamiento conservador y el conservadurismo mexicano (Tomo I).

México: Universidad Nacional Autónoma de México.

Ríos, R. (2002)

Formar ciudadanos. Sociedad civil y movilización popular en Zacatecas (1821-1854). México: Universidad Nacional Autónoma de México/ Plaza y Valdés.

Rojas, B. (2010)

El municipio libre. Una utopía perdida en el pasado. Los pueblos de Zacatecas, 1786-1835. México: Instituto Mora/Instituto Cultural de Aguascalientes/Colegio de Bachilleres del Estado de Zacatecas.

Rojas, B. (2015)

El derecho de petición y el sistema representativo mexicano. Istor (61), 159-186.

Sánchez de Tagle, M. (1835)

Discurso sobre la creación de un Poder Conservador. México: Impreso por acuerdo del Congreso General en la imprenta de J. M. Fernández de Lara.

Soberanes, J. (1998)

La Constitución Yucateca de 1841 y su juicio de amparo. En VV.AA. Liber ad honorem Sergio García Ramírez (pp. 647-655). México: Universidad Nacional Autónoma de México.

Sordo, R. (1993)

El congreso en la primera república centralista. México: El Colegio de México, Instituto Tecnológico Autónomo de México.

Pantoja, D. (2005)

El Supremo Poder Conservador. El diseño institucional en las primeras 
constituciones mexicanas. México: El Colegio de México, El Colegio de Michoacán.

Terán, M. (2015)

Bosquejo de un inmenso cuadro. Liberalismo constitucional y formas de gobierno en Zacatecas, 1823-1846. México: Universidad Autónoma de Zacatecas, Consejo Nacional de Ciencia y Tecnología.

Vázquez, J. (1987)

Planes en la nación mexicana, 1831-1854 (Volumen IV, pp. 28-47). México: Senado de la República, El Colegio de México.

Vázquez, J. (1993)

El federalismo mexicano, 1823-1847. En M. Carmagnani (Coord.), Federalismos latinoamericanos. México, Brasil, Argentina (pp. 15-50). México: Fondo de Cultura Económica, El Colegio de México, Fideicomiso Historia de las Américas.

Vázquez, J. (1996)

El fracaso del liberalismo centralista mexicano. Anuario del Instituto de Estudios Histórico Sociales (11), 109-121.

Vázquez, J. (2015)

Francisco García Salinas y el fracaso del federalismo (Cuadernos de la Cátedra Internacional de Federalismo "Francisco García Salinas"). México: Universidad Autónoma de Zacatecas, Consejo Nacional de Ciencia y Tecnología.

Vega, M. (2006)

Los dilemas de la organización autónoma. Zacatecas, 1808-1835. México: El Colegio de México. 